\title{
Laboratory measurements and model sensitivity studies of dust deposition ice nucleation
}

\author{
G. Kulkarni, J. Fan, J. M. Comstock, X. Liu, and M. Ovchinnikov \\ Atmospheric Sciences and Global Change Division, Pacific Northwest National Laboratory, Richland, WA, 99352, USA \\ Correspondence to: G. Kulkarni (gourihar.kulkarni@pnnl.gov)
}

Received: 7 September 2011 - Published in Atmos. Chem. Phys. Discuss.: 25 January 2012

Revised: 15 July 2012 - Accepted: 27 July 2012 - Published: 16 August 2012

\begin{abstract}
We investigated the ice nucleating properties of mineral dust particles to understand the sensitivity of simulated cloud properties to two different representations of contact angle in the Classical Nucleation Theory (CNT). These contact angle representations are based on two sets of laboratory deposition ice nucleation measurements: Arizona Test Dust (ATD) particles of 100, 300 and $500 \mathrm{~nm}$ sizes were tested at three different temperatures $(-25,-30$ and $-35^{\circ} \mathrm{C}$ ), and $400 \mathrm{~nm}$ ATD and kaolinite dust species were tested at two different temperatures $\left(-30\right.$ and $\left.-35^{\circ} \mathrm{C}\right)$. These measurements were used to derive the onset relative humidity with respect to ice $\left(\mathrm{RH}_{\text {ice }}\right)$ required to activate $1 \%$ of dust particles as ice nuclei, from which the onset single contact angles were then calculated based on CNT. For the probability density function (PDF) representation, parameters of the log-normal contact angle distribution were determined by fitting CNT-predicted activated fraction to the measurements at different $\mathrm{RH}_{\text {ice }}$. Results show that onset single contact angles vary from $\sim 18$ to 24 degrees, while the PDF parameters are sensitive to the measurement conditions (i.e. temperature and dust size). Cloud modeling simulations were performed to understand the sensitivity of cloud properties (i.e. ice number concentration, ice water content, and cloud initiation times) to the representation of contact angle and PDF distribution parameters. The model simulations show that cloud properties are sensitive to onset single contact angles and PDF distribution parameters. The comparison of our experimental results with other studies shows that under similar measurement conditions the onset single contact angles are consistent within \pm 2.0 degrees, while our derived PDF parameters have larger discrepancies.
\end{abstract}

\section{Introduction}

Ice containing clouds constitute one of the largest sources of uncertainty in predicting the Earth's climate according to the Intergovernmental Panel on Climate Change (IPCC) 2007 report (Forster et al., 2007). The uncertainty arises in part because of the lack of understanding of the complex processes governing the formation of these clouds. Ice microphysics has important impacts on precipitation and Earth's radiative balance by altering cloud microphysical and radiative properties. Ice formation at temperatures below about $-37^{\circ} \mathrm{C}$ occurs via both homogeneous and heterogeneous ice nucleation mechanisms, while at warmer temperatures ice nucleation takes place only heterogeneously. Our understanding of homogeneous nucleation has improved dramatically over the last decades (e.g., Heymsfield and Miloshevich, 1995; Tabazadeh et al., 1997; Koop et al., 2000). Although advancements in heterogeneous ice nucleation measurements and parameterizations have been reported (e.g. Kanji et al., 2011; Wang and Knopf, 2011; DeMott et al., 2010 and references therein), heterogeneous ice formation is still puzzling. There are at least two reasons why heterogeneous ice nucleation is much more complex than homogeneous freezing. First, it requires special atmospheric aerosols, called ice nuclei (IN) (Pruppacher and Klett, 1997), which lower the free energy barrier for ice nucleation. Aerosol surface characteristics, such as morphology, solubility, active sites and epitaxial properties, have been postulated to play important roles in determining the IN efficiency of aerosol particles, but formulating a relationship among these characteristics has been difficult. Second, there are multiple heterogeneous ice nucleation mechanisms observed or hypothesized (Vali, 1985), such as deposition nucleation (ice formation directly from the 
vapor phase), condensation and immersion freezing (freezing initiated by the IN located within the supercooled water or solution droplet), and contact freezing (freezing occurring at the moment IN comes into contact with a supercooled water droplet or solution droplet). The relative importance of each mechanism in producing ice particles at given meteorological conditions is not well understood.

Although heterogeneous ice formation is complex, several parameterizations, with or without a link to physiochemical properties (chemistry and surface characteristics) of an individual IN, have been developed. These existing parameterizations can be broadly classified into two categories: empirical parameterizations that use laboratory or field measurements (e.g., Meyers et al., 1992; Diehl and Wurzler, 2004; Phillips et al., 2008; DeMott et al., 2010), and those that are based on the classical nucleation theory (CNT) (e.g., Khvorostyanov and Curry, 2000, 2004; Liu and Penner, 2005). Empirical parameterizations are appealing because they are easy to implement and computationally efficient for regional/global models, but these schemes often have limited temperature and/or supersaturation ranges where they can be applied. In the CNT approach, the nucleability of IN can be quantified in terms of contact angle. For the deposition ice nucleation mode, the contact angle of an ice embryo on an IN represents a relationship between the surface energies defined at the water vapor - ice, water vapor - catalyzing substrate and ice - catalyzing substrate interfaces (Fletcher, 1962). The approach is based on the assumption that all IN have the equal probabilities to nucleate ice and behave in a purely stochastic fashion, which implies time dependence. Thus, the differences in surface properties among IN are neglected. Several past studies have calculated the single value of contact angle under various ice nucleation conditions (e.g. Eastwood et al., 2008; Welti et al., 2009; Kanji and Abbatt, 2010; Kulkarni and Dobbie, 2010). This approach has the advantage that contact angle derived from various IN can be compared by formulating a deposition ice nucleation parameterization as a function of relative humidity (e.g. Wang and Knopf, 2011). Recently, CNT approach was implemented in a global climate model and used for long-term climate simulations (Hoose et al., 2010). It should be noted that parameters such as the magnitudes of elastic strain, aerosol surface irregularities and active sites may affect the ice nucleation behavior of dust particles, but are not included in CNT calculations and are ignored in this study. We also recognize that previous studies (e.g. Connolly et al., 2009; Niedermeier et al., 2011) have formulated new parameterizations based on the ice-active surface site density approach, which is also not considered here.

The original framework of CNT can be generalized to incorporate the variability in surface properties of IN by assuming a PDF distribution of contact angles over the entire dust sample instead of using a single contact angle (e.g., Marcolli et al., 2007). This modified approach using a log-normal PDF was employed by Lüönd et al. (2010) to constrain the laboratory immersion ice nucleation data. CNT was further modified by Niedermeier et al. (2011), where instead of a distribution of contact angles over the entire dust sample, they described a conceptual model that treats each particle consisting of a distribution of surface sites or properties of IN. They concluded that ice nucleation parameterizations that are based on the stochastic theory might be influenced by the heterogeneity of surface properties depending upon the time and freezing temperatures. More recently Wheeler and Bertram (2012) used onset $\mathrm{RH}_{\mathrm{ice}}$ and particle surface area distribution to test the PDF approach against the single contact angle model, the active site model and the deterministic model for deposition ice nucleation. They showed that using a single contact angle based on the onset $\mathrm{RH}_{\text {ice }}$ does not fit the data well, while the PDF distributed contact angle model fits the data within experimental uncertainties. Connolly et al. (2009) developed a new parameterization based on laboratory heterogeneous ice nucleation data. Unlike the CNT approach, their model is based on the singular theory, or deterministic approach. In this approach it is assumed that particles have multiple nucleation sites where ice could form and the most efficient nucleation site determines the ice formation rate. In deposition ice nucleation experiments, as soon as any of those nucleation sites reach the characteristics $\mathrm{RH}_{\mathrm{ice}}$, the ice will form immediately and if this characteristic $\mathrm{RH}_{\text {ice }}$ is held constant, then no further ice nucleation events should occur, suggesting there is no time dependence. Based on the particle surface area Niemand et al., (2012) developed a new parameterization to parameterize the immersion freezing of desert dust particles in the temperature range between $-12^{\circ} \mathrm{C}$ and $-36^{\circ} \mathrm{C}$. They implemented the parameterization into a model, and compared the calculated aerosol size distributions and IN number concentrations with the measurements. They also compared their results with other three existing parameterizations. While the calculations show a good agreement with the aerosol surface area measurements, discrepancies among the IN concentrations detected by the IN device were observed. Comparison of parameterizations showed that particle surface area dependent parameterization is highly sensitive to the simulated temperatures, and agrees with the other parameterizations and measurements at certain temperature values. Recently, Ervens and Feingold (2012) explored the sensitivity of time-dependent CNT parameterizations against singular freezing theories in a box model that simulated immersion and condensation freezing mechanisms. They showed that predicted ice number concentrations from different ice nucleation schemes are sensitive to the parameters such as time, size of IN, temperature and supersaturation, and suggested that these parameters should be better constrained to simulate realistic cloud properties.

Two empirical fits for the $\mathrm{RH}_{\text {ice }}$ dependence of deposition ice nucleation have been reported in literature. Möhler et al. (2006) suggested the exponential fit framework, similar to Meyers et al. (1992), whereas Welti et al. (2009) suggested a sigmoidal fit curve. Both approaches were constrained using 
laboratory measurement data. Welti et al. (2009) showed that the Möhler et al. (2006) approach does not fit their data well, possibly because of different measurement conditions and experimental techniques. These fit curve formulations can be further improved by finding a universal fit function that can be adapted to deposition ice nucleation measurements of various IN sizes as a function of temperature and $\mathrm{RH}_{\text {ice }}$. Here we show that a modified CNT approach can be used to find such fit functions using deposition ice nucleation measurements. The approach is based on the modified CNT approach of Lüönd et al. (2010), but the PDF distribution of contact angles is constrained by the laboratory data on deposition ice nucleation rather than immersion freezing. For the CNT calculations the ice nucleation time is restricted to the particle residence time within the ice nucleation chamber $(\sim 12 \mathrm{~s}$; see Sect. 2).

In this study, we experimentally investigate the ice nucleating properties of mineral dust particles and examine the impact of the nucleation properties within the original and modified CNT framework on cloud properties simulated with an offline module and a cloud resolving model (CRM). Two types of mineral dust particles were investigated for their nucleation properties: ATD and kaolinite. Deposition ice nucleation measurements of mineral dust particles were carried out using the compact ice chamber (CIC) at the Pacific Northwest National Laboratory (PNNL) Atmospheric Measurement Laboratory. These measurements, together with the data from past studies (Welti et al., 2009), were used to calculate the single contact angle and PDF parameters (mean and standard deviation) of the contact angle distribution. The sensitivity to these ice nucleating characteristics and broader implications of the CNT modifications are examined in the context of CRM simulated cloud properties: the ice number concentration $\left(N_{i}\right)$, ice water content (IWC) and cloud evolution.

In the rest of the paper, Sect. 2 describes the experimental method to obtain the ice nucleating properties of dust particles, presents the methodology for determining the PDF parameters from the contact angle distribution, and provides a description of the model and simulation cases. Section 3 includes the results of contact angle and PDF calculations based on CIC measurements and a sensitivity analysis of the change in cloud properties to changes in the onset single contact angle and PDF parameters. The PDF parameters are also compared with the parameters derived from the literature data under similar measurement conditions (temperature, $\mathrm{RH}_{\text {ice }}$, dust type and size). Finally, the summary and future research directions are presented in Sect. 4.

\section{Methodology}

\subsection{Ice nucleation experiments}

The experimental data on ice nucleation were obtained using the recently developed CIC. The basic design and functional details of the CIC are described in Stetzer et al. (2008) and Friedman et al. (2011). The chamber consists of two vertical parallel plates with an evaporation section attached at the bottom of the chamber to remove water droplets (Stetzer et al., 2008). The principle of a continuous flow water vapor diffusion chamber ensures that aerosol particles that are placed between the layers of two sheath flows are exposed to constant temperature and $\mathrm{RH}_{\text {ice }}$ over the length of the chamber. The chamber wall temperatures are controlled using two external cooling baths (Lauda Brinkmann Inc.) and the temperature data are logged using the National Instrument CompactRIO programmable automation controller (cRIO-9114 combined with cRIO-9022). The chamber plates are independently temperature- controlled to develop a linear temperature gradient across them, which according to the principle of thermal gradient diffusion theory, produces a $\mathrm{RH}_{\text {ice }}$ profile between the plates (e.g. Rogers et al., 1988). At the beginning of the experiment, the chamber walls are coated with an ice layer ( $\sim 0.5 \mathrm{~mm}$ thick) and the temperature gradient is set at zero, which creates ice saturation conditions inside the chamber $\left(\mathrm{RH}_{\mathrm{ice}}=100 \%\right)$, and then the refrigeration system cools one plate and warms the other to increase the $\mathrm{RH}_{\text {ice }}$. The total flow used is $11 \mathrm{Lpm}$; sheath and sample flows used are 10 and $1 \mathrm{Lpm}$, respectively, which limits the aerosol residence time to $\sim 12 \mathrm{~s}$ within the CIC. Ice nucleates on the aerosol particles and the newly formed ice crystal grows to a size greater than the original aerosol size, and ice crystals greater than 1 micrometer exiting the chamber are counted with an optical particle counter (OPC; CLiMET, model CI-3100).

A schematic of the experimental setup is shown in Fig. 1. ATD (Powder Technology, Inc) and kaolinite (SigmaAldrich) dust samples were used in the experiments. These dust particles are dry-dispersed (dry powder dispersion; TSI, 3433) and size-selected by a differential mobility analyzer (DMA; TSI, 3080). Different sizes of particles at 100, 300, 400 and $500 \mathrm{~nm}$ diameters, respectively, are selected and forwarded to the CIC and Condensation Particle Counter (CPC; TSI, 3010). It was observed that selected size particle sample flow consists of multiple charged particles. For $100 \mathrm{~nm}$ diameter selected particles, the DMA produced particles with sizes of $152 \mathrm{~nm}$ (the size of double charged particles) and $197 \mathrm{~nm}$ (the size of triple charged particles), and their contribution was $36 \%$ and $16 \%$, respectively. For 300, 400 and $500 \mathrm{~nm}$ diameter selected particles, the contribution of multiple charged particles was less than $10 \%$. For sizes 100 and $300 \mathrm{~nm}$ diameter particles, the multiple charge calculations were based on routine experimental measurements, whereas for 400 and $500 \mathrm{~nm}$ diameter particles the calculations are based on the Baron and Willeke (2001). An active fraction 
Table 1. PDF parameters, onset ice nucleation conditions and RMSE obtained for ATD. One experiment was performed at each temperature and dust size. The range of onset single contact angle $(\theta)$ variation was minimum compared to the $\mu$ parameter. The uncertainty errors for $\mu$ and $\sigma$ are $\pm 3.0 \mathrm{deg}$ and $\pm 0.04 \mathrm{rad}$, respectively.

\begin{tabular}{l|ccc|ccc|ccc}
\hline Dust size & \multicolumn{3}{|c|}{$100 \mathrm{~nm}$} & \multicolumn{3}{c|}{$300 \mathrm{~nm}$} & \multicolumn{3}{|c}{$500 \mathrm{~nm}$} \\
\hline$T\left({ }^{\circ} \mathrm{C}\right)$ & -25 & -30 & -35 & -25 & -30 & -35 & -25 & -30 & -35 \\
$\mu(\mathrm{deg})$ & 56.0 & 38.0 & 38.0 & 27.0 & 57.0 & 36.0 & 45.0 & 64.0 & 32.0 \\
$\sigma(\mathrm{rad})$ & 0.31 & 0.21 & 0.19 & 0.05 & 0.29 & 0.19 & 0.25 & 0.41 & 0.12 \\
Onset $\mathrm{RH}_{\text {ice }}(\%)$ & 132 & 130 & 131 & 130 & 126 & 125 & 128 & 127 & 126 \\
Onset $\theta(\mathrm{deg})$ & 23.0 & 24.0 & 24.0 & 22.5 & 22.0 & 22.0 & 22.5 & 23.0 & 21.0 \\
RMSE $(\%)$ & 0.06 & 0.71 & 0.48 & 0.07 & 0.77 & 0.52 & 0.38 & 0.56 & 1.52 \\
\hline
\end{tabular}

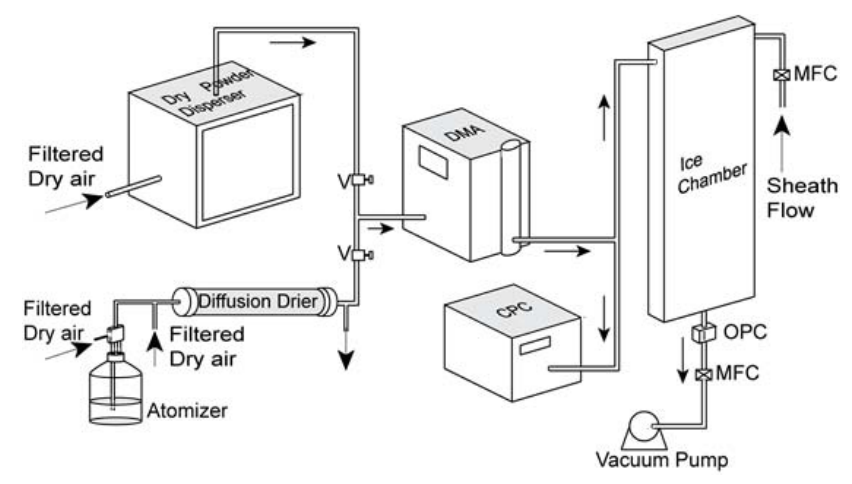

Fig. 1. Experimental setup used to determine the IN fraction of dust particles. The ATD particles are dry dispersed size selected and investigated for their ice nucleation efficiency. The atomizer set up is used to validate the temperature and $\mathrm{RH}_{\text {ice }}$ conditions within the CIC (data not shown here). The polydisperse particles of ammonium sulfate were generated in the atomizer, and passed through the drier to remove any water droplets and water residing on the ammonium sulfate particles. The sample flow is forwarded to the DMA and consequently to CIC and CPC. The remainder of the flow went to the exhaust. The valve (V) was used to switch between these two types of experiments. The mass flow controller (MFC) was used to regulate the CIC flows.

$\left(F_{\text {ice }}\right)$ is calculated as the ratio of the number of ice crystals measured by the OPC to the total number of particles entering the chamber, as measured by the CPC. $F_{\text {ice }}$ calculations are corrected for the particle losses, averaged over $\pm 0.5 \%$ relative humidity with respect to water, and plotted as a function of $\mathrm{RH}_{\text {ice }}$ (e.g. shown in Fig. 2). The experimental $\mathrm{RH}_{\text {ice }}$ uncertainty is $\sim \pm 3 \%$ that arises from the uncertainty of temperature $\left(< \pm 0.4{ }^{\circ} \mathrm{C}\right)$ measurements.

\subsection{PDF-contact angle model}

CNT provides a framework to parameterize deposition ice nucleation measurements. This framework was modified to adopt the PDF approach for contact angle distribution from Lüönd et al. (2010), and this modified CNT framework was used to derive the PDF parameters that parameterize the measurements, as illustrated in Eq. (1) to (4) below.

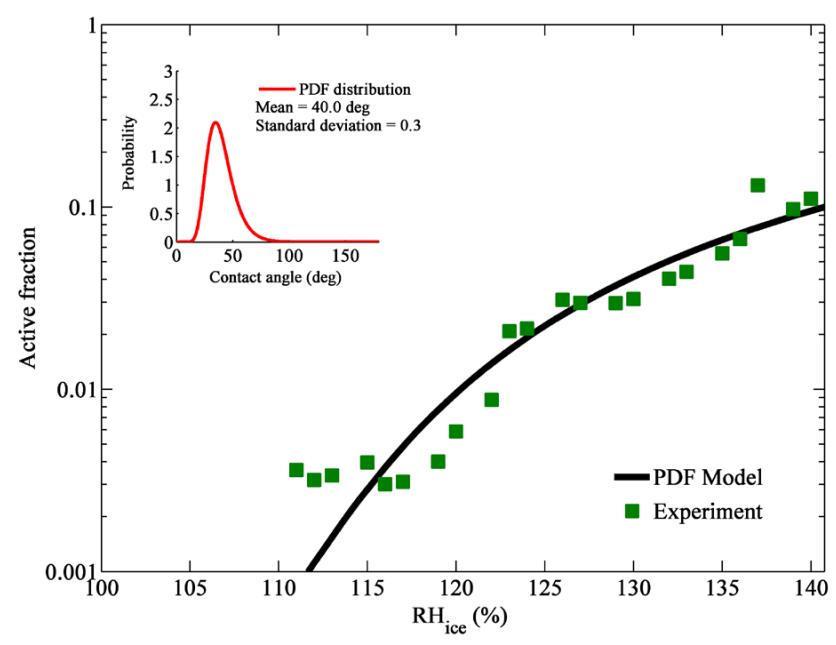

Fig. 2. Active fraction $\left(F_{\text {ice }}\right)$ of ATD particles, at $-35^{\circ} \mathrm{C}$ and $400 \mathrm{~nm}$ in diameter (Table 2), is given as a function $\mathrm{RH}_{\mathrm{ice}}$. The solid curve shows the PDF model fit to the experimental data points. The inset shows the PDF distribution with corresponding parameters. The error for $\mathrm{RH}_{\text {ice }}$ is approximately $\pm 3 \%$.

According to CNT, the deposition nucleation rate, $J$, of critical ice embryos per unit area per unit time is given in Pruppacher and Klett (1997) as,

$J\left(S_{v, i}, \theta\right)=A_{0} \exp \left(-\frac{16 \pi M_{\mathrm{w}}^{2} \sigma_{i / v}^{3}}{3\left(\mathrm{RT} \rho_{i} \ln S_{v, i}\right)^{2}} \cdot \frac{f_{\text {het }}}{k T}\right)$

If the contact angle distribution is assumed to be log-normal (Marcolli et al., 2007), then the PDF function, $p(\theta)$, of contact angle, $\theta$, is given as (Crowe, 2006),

$p(\theta)=\frac{1}{\theta \sigma \sqrt{ } 2 \pi} \exp \left(-\frac{(\ln (\theta)-\ln (\mu))^{2}}{2 \sigma^{2}}\right)$

Then nucleated fraction from the PDF- $\theta$ model, $F_{\text {ice }}^{\text {mod }}$, can be calculated:

$F_{\text {ice }}^{\text {mod }}=1-\int_{0}^{\pi} p(\theta) \cdot \exp \left(-4 \pi r^{2} \cdot J\left(S_{v, i}, \theta\right) t\right) \cdot d \theta$ 
Table 2. Comparison of derived PDF parameters and onset single contact angle $(\theta)$ calculated at two temperatures and dust types (of size $400 \mathrm{~nm}$ ) with Welti et al. (2009). Possible sources of disagreement are outlined in the text. The data highlighted in bold are used to plot the PDF distribution shown in Fig. 2. The uncertainty errors for $\mu$ and $\sigma$ are $\pm 3.0 \mathrm{deg}$ and $\pm 0.04 \mathrm{rad}$, respectively.

\begin{tabular}{l|cccc|cccc}
\hline Group & \multicolumn{4}{|c|}{ This study } & \multicolumn{3}{c}{ Welti et al. (2009) } \\
\hline Dust & \multicolumn{2}{|c}{ ATD } & kaolinite & \multicolumn{2}{c}{ ATD } & kaolinite \\
\hline$T\left({ }^{\circ} \mathrm{C}\right)$ & -30 & $-\mathbf{3 5}$ & -30 & -35 & -30 & -35 & -30 & -35 \\
$\mu(\mathrm{deg})$ & 33.0 & $\mathbf{4 0 . 0}$ & 62.0 & 56.0 & 40.0 & 22.0 & 58.0 & 28.0 \\
$\sigma(\mathrm{rad})$ & 0.21 & $\mathbf{0 . 3 0}$ & 0.5 & 0.49 & 0.295 & 0.065 & 0.36 & 0.29 \\
Onset $\mathrm{RH}_{\text {ice }}(\%)$ & 117 & 121 & 121 & 115 & 121 & 120 & 130 & 112 \\
Onset $\theta(\mathrm{deg})$ & 18.0 & 20.0 & 20.0 & 17.5 & 20.0 & 20.0 & 23.0 & 17.0 \\
RMSE $(\%)$ & 1.05 & 1.4 & 0.73 & 1.26 & 0.38 & 0.34 & 0.22 & 0.68 \\
\hline
\end{tabular}

where in Eqs. (1), (2) and (3): $r$ is the aerosol radius in meters, $t$ is the aerosol residence time inside the CIC in seconds, $\sigma$ and $\mu$ are the logarithmic standard deviation and geometric mean of the PDF contact angle distribution, respectively, $M_{\mathrm{W}}$ is the molar mass of water $\left(=0.018016 \mathrm{~kg} \mathrm{~mol}^{-1}\right), \sigma_{i / v}$ is the interfacial surface tension between the ice-vapor interface $\left(=0.106 \mathrm{~J} \mathrm{~m}^{-2}\right), R$ is the universal gas constant $\left(=8.314 \mathrm{~J} \mathrm{~K}^{-1} \mathrm{~mol}^{-1}\right), S_{v, i}$ is the saturation ratio with respect to ice (i.e., $\mathrm{RH}_{\mathrm{ice}}$ ), $k$ is the Boltzmann constant $\left(=1.380622 \times 10^{-23}, \mathrm{~J} \mathrm{~K}^{-1}\right), f_{\text {het }}$ is the compatibility parameter given as $f_{\text {het }}=(2+m)(1-m)^{2} / 4, m$ is defined as $\cos (\theta)$, $T$ is the temperature and $A_{0}$ is the pre-exponential factor, $A_{0}=10^{29} \mathrm{~m}^{-2} \mathrm{~s}^{-1}$.

The PDF approach assigns a single contact angle for each IN, and the probability of occurrence of these contact angles is given by a PDF distribution. The methodology to obtain the PDF parameters that best describes the experimental data is as follows. The integral form of Wq. 3) was discretized into 2000 bins. Then for the given measurement conditions (temperature, $r, t, S_{v, i}$ ), the PDF distribution parameters, $\sigma$ and $\mu$, were iterated to find the best fit between $F_{\text {ice }}^{\bmod }$ and $F_{\text {ice }}$ values by minimizing the root mean square error (RMSE) between them. The RMSE was calculated as:

RMSE $=\sqrt{\frac{1}{N} \sum_{1}^{N}\left[F_{\text {ice }}-F_{\text {ice }}^{\text {mod }}\right]^{2}}$

Where $N$ is total number of data points. The PDF fit parameters that are associated with the least RMSE are given in Tables 1 and 2 as a function of measurement conditions. Fig. 2 shows $F_{\text {ice }}^{\text {mod }}$ curve and $F_{\text {ice }}$ values for measurement conditions at $-35^{\circ} \mathrm{C}$ and $400 \mathrm{~nm}$ size ATD particles, and the inset shows the associated PDF distribution.

Onset single contact angle based on the onset $\mathrm{RH}_{\text {ice }}$ (i.e. the value of $\mathrm{RH}_{\text {ice }}$ measured at $F_{\text {ice }}=1 \%$ ) can be calculated as follows:

$F_{\text {ice }}=1-\exp \left(-4 \pi r^{2} \cdot J\left(S_{v, i}, \theta\right) \cdot t\right)$

Equations (1) and (5) are solved to calculate the $\theta$ (onset single contact angle) at various measurement conditions (tem-

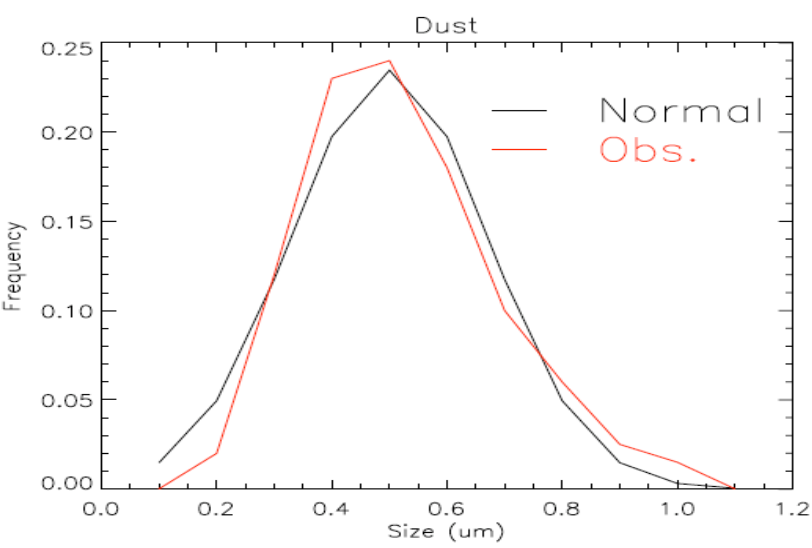

Fig. 3. The normalized size distribution observed in Cziczo et al. (2006) (red) and the fitted normal distribution used in the model simulations (black). The integrated dust number concentration, $N_{0}$, is $10.7 \mathrm{~L}^{-1}$.

perature, $\left.r, t, S_{v, i}\right)$ and are given in Tables 1 and 2. For these calculations the onset $\mathrm{RH}_{\text {ice }}$ values were directly computed from the PDF modeled fitted curve. For example, the onset $\mathrm{RH}_{\text {ice }}$ for the data shown in Fig. 2 is $\sim 121 \%$.

\subsection{Description of model and the simulated case}

Two sets of simulations were carried out to examine the sensitivity of modeled cloud properties to different representations of contact angles in CNT.

First, we ran offline module tests for the PDF- $\theta$ and onset single contact angle based CNT parameterizations to calculate the ice number concentration $\left(N_{\text {ice }}^{\text {model }}\right)$ using a dust size distribution from Cziczo et al. (2006) (Fig. 3), temperature, $\mathrm{RH}_{\mathrm{ice}}$, and the PDF parameters (Table 1) with an integration time step of $2 \mathrm{~s}$. In the module tests for the PDF- $\theta$ parameterization, we calculated $F_{\text {ice }}^{\text {mod }}$ and $F_{\text {ice }}$ from Eqs. (3) and (5), respectively. We chose the dust size distribution from $\mathrm{Cz}$ iczo et al. (2006) with total dust concentrations $\left(N_{0}\right)$ of about $10.7 \mathrm{~L}^{-1}$. The $N_{0}$ was calculated by integrating the observed dust size distribution (Fig. 3). 
In the second set of simulations, we conducted sensitivity studies using a cloud-resolving model (CRM) that has the dynamical framework of a large-eddy simulation model and a spectral-bin microphysical scheme (Khain et al., 2004; Fan et al., 2009) to simulate a stratiform/cirrus case (Comstock et al., 2007). Briefly, the CRM solves an equation system for eight number size distributions for water drops, ice crystals (columnar, plate-like, and dendrites), snowflakes, graupel, hail/frozen drops, and CCN. Each size distribution is represented by 33 mass doubling bins, i.e. the mass of a particle $m_{k}$ in the $k$ bin is determined as $m_{k}=2 m_{k-1}$. All relevant microphysical processes/interactions including droplet nucleation, primary and secondary ice generation, condensation/evaporation of drops, deposition/sublimation of ice particles, freezing/melting, and mutual collisions between the various hydrometeors were calculated explicitly. The dependence of the collision efficiencies on height and the effects of turbulence on the rate of collisions were taken into account. An updated remapping scheme has been used that conserves three moments of the hydrometeor size distributions (concentration, mass, and radar reflectivity) to reduce spectral broadening and be more consistent with observations (Khain et al., 2008).

The PDF- $\theta$ and onset single contact angle based CNT parameterizations for deposition ice nucleation (as described in Sect. 2.2) were implemented into CRM for use in the sensitivity studies, turning off all the other ice nucleation schemes. The onset single contact angle was increased from 5 to 30 degrees with an interval of 5 degrees. A series of sensitivity tests by varying the PDF parameters were undertaken, and finally a sensitivity test to the $N_{0}$ was performed (Table 3 ) to compare the change in cloud properties caused by the initial $N_{0}$ with the fixed PDF parameters.

The stratiform/cirrus cloud case observed from the US Department of Energy's Atmospheric Radiation Measurement (ARM) facility located at the South Great Plain site on March 09, 2000 (Comstock et al., 2007) is chosen to test deposition ice nucleation. Simulations were run on a two-dimensional computational domain comprised of 72 horizontal grid points and 60 vertical layers with a horizontal resolution of $200 \mathrm{~m}$ and stretched vertical resolutions. Periodic lateral boundary conditions were used. The dynamic time step is $2 \mathrm{~s}$. All simulations were run for $12 \mathrm{~h}$, starting from 1500 on 9 March (UTC). The thermodynamic sounding and large-scale forcing data employed to drive the model are available from the ARM Archive.

\section{Results and discussion}

\subsection{Onset ice nucleation and PDF parameter calculations}

The ice nucleating properties of different sizes of ATD particles were investigated in a laboratory at various tempera-
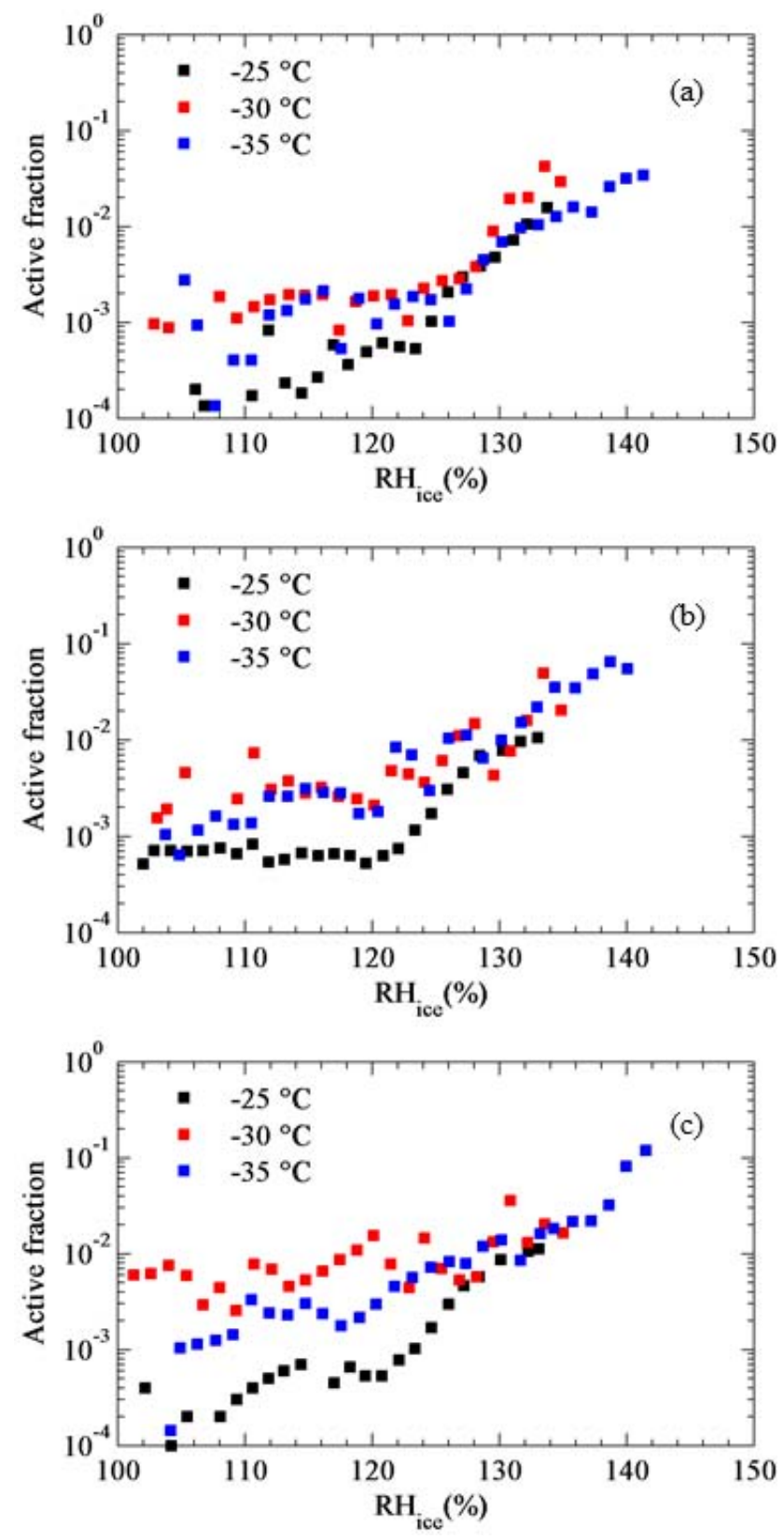

Fig. 4. Active fraction of ATD particles as a function of $\mathrm{RH}_{\text {ice }}(\%)$. Three different size particles were investigated at temperatures of $-25,-30$ and $-35^{\circ}$ C. (a), (b) and (c) corresponds to the $100 \mathrm{~nm}$, $300 \mathrm{~nm}$ and $500 \mathrm{~nm}$ diameter particles, respectively.

tures (Fig. 4). The results suggest that $F_{\text {ice }}$ increases with $\mathrm{RH}_{\text {ice, }}$, which is also dependent on temperature. For all the ATD sizes investigated, $F_{\text {ice }}$ magnitudes at colder temperature $\left(-30\right.$ and $\left.-35^{\circ} \mathrm{C}\right)$ are larger than at $-25^{\circ} \mathrm{C}$. Further, the ice nucleating properties of ATD and kaolinite dust particles of $400 \mathrm{~nm}$ size at -30 and $-35^{\circ} \mathrm{C}$ were also investigated (Fig. 5). These results also show that $F_{\text {ice }}$ increases with an increase in $\mathrm{RH}_{\mathrm{ice}}$, similar to ice nucleating properties observed in Fig. 4. 
Table 3. Cloud sensitivity tests of $\mu(\mathrm{deg}), \sigma(\mathrm{rad})$ and $N_{0}\left(\mathrm{~L}^{-1}\right)$ variables. Three cases were simulated. In the case 3 simulations the parameters $\mu$ and $\sigma$ are 33.0 and $0.41 \mathrm{rad}$, respectively, were held constant.

\begin{tabular}{cc|cc|cc}
\hline \multicolumn{2}{c|}{ Case 1 } & \multicolumn{2}{c|}{ Case 2 } & \multicolumn{2}{c}{ Case 3 } \\
\hline Simulations & $\mu$ with $\sigma=0.14$ & Simulations & $\sigma$ with $\mu=23.0$ & Simulations & $N_{0}$ \\
\hline MU1 & 38.0 & SD1 & 0.14 & IN0 & $N_{0}=10.7 L^{-1}$ \\
MU2 & 33.0 & SD2 & 0.22 & IN1 & $3 \times N_{0}$ \\
MU3 & 28.0 & SD3 & 0.30 & IN2 & $6 \times N_{0}$ \\
MU4 & 23.0 & SD4 & 0.38 & IN3 & $10 \times N_{0}$ \\
MU5 & 18.0 & - & - & - & - \\
\hline
\end{tabular}

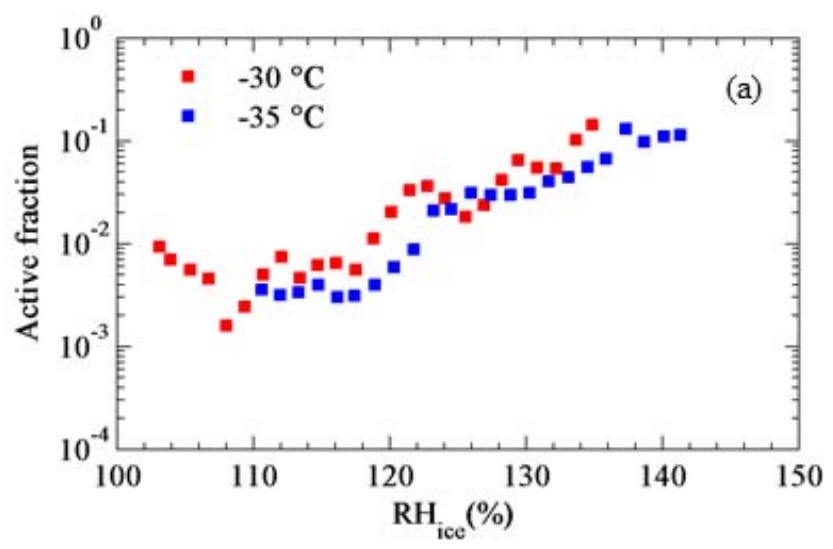

the correlation between PDF parameters is low, we were unable to derive a relationship suitable for implementation into the cloud model.

As described in the Sect. 2.2, the PDF- $\theta$ parameterization assigns a single contact angle for each IN, and the best fit PDF parameters produce a probability of occurrences of these contact angles that is given by a PDF distribution. Thus, the PDF distribution represents the spectra of activated fraction. Past studies (e.g. Kanji and Abbatt, 2010 and references therein), including the present study, have shown that ice nucleating properties of dust particles vary with size and temperature. The size effect could be attributed to the increased probability of finding active sites that are capable of initiating the ice phase with larger particle sizes, whereas tem-

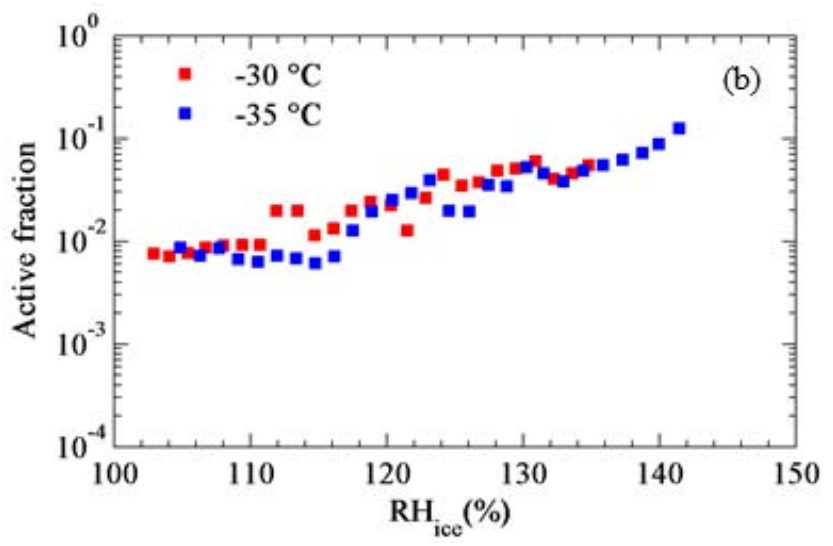
perature might influence the rate of ice embryo formation at these sites (Pruppacher and Klett, 1997). Therefore, if the activation properties of dust particles vary (see Fig. 4), then the PDF parameters also vary and may explain the scattering of the PDF parameters shown in Tables 1 and 2. It should be also noted that the particles having the smallest contact angle will induce nucleation first and other particles will activate later, when favorable conditions exist. The sensitivity of cloud properties to such contact angle distribution will be explored in Sect. 3.3.

The onset single contact angle results (Tables 1 and 2) indicate that the IN ability does not vary over the range of temperatures and three dust sizes studied here. Under the conditions that we carried out our experiments, the onset $\mathrm{RH}_{\text {ice }}$ varied from 115 to $132 \%$ and the respective single contact angles varied between $\sim 18$ and 24 degrees. The dependency of these contact angles on the onset $\mathrm{RH}_{\mathrm{ice}}$ is in agreement with a previous study (Wang and Knopf, 2011) that parameterized the deposition ice nucleation as a function of $\mathrm{RH}_{\text {ice }}$ (Fig. S1, carried forward in the Supplement). The deposition ice nucleation onset has been shown to be insensitive to the experimental temperatures $\left(-25\right.$ to $\left.-35^{\circ} \mathrm{C}\right)$ in past studies (e.g. Kanji and Abbatt, 2006; Kulkarni and Dobbie, 2010) for dust particles. This might be because the ice nucleating abilities of active sites (assuming active sites are favorable locations where water vapor can deposit and form ice) are insensitive to temperature. The fact that we did not observe a particle size dependence based on the onset $\mathrm{RH}_{\text {ice }}$, which 

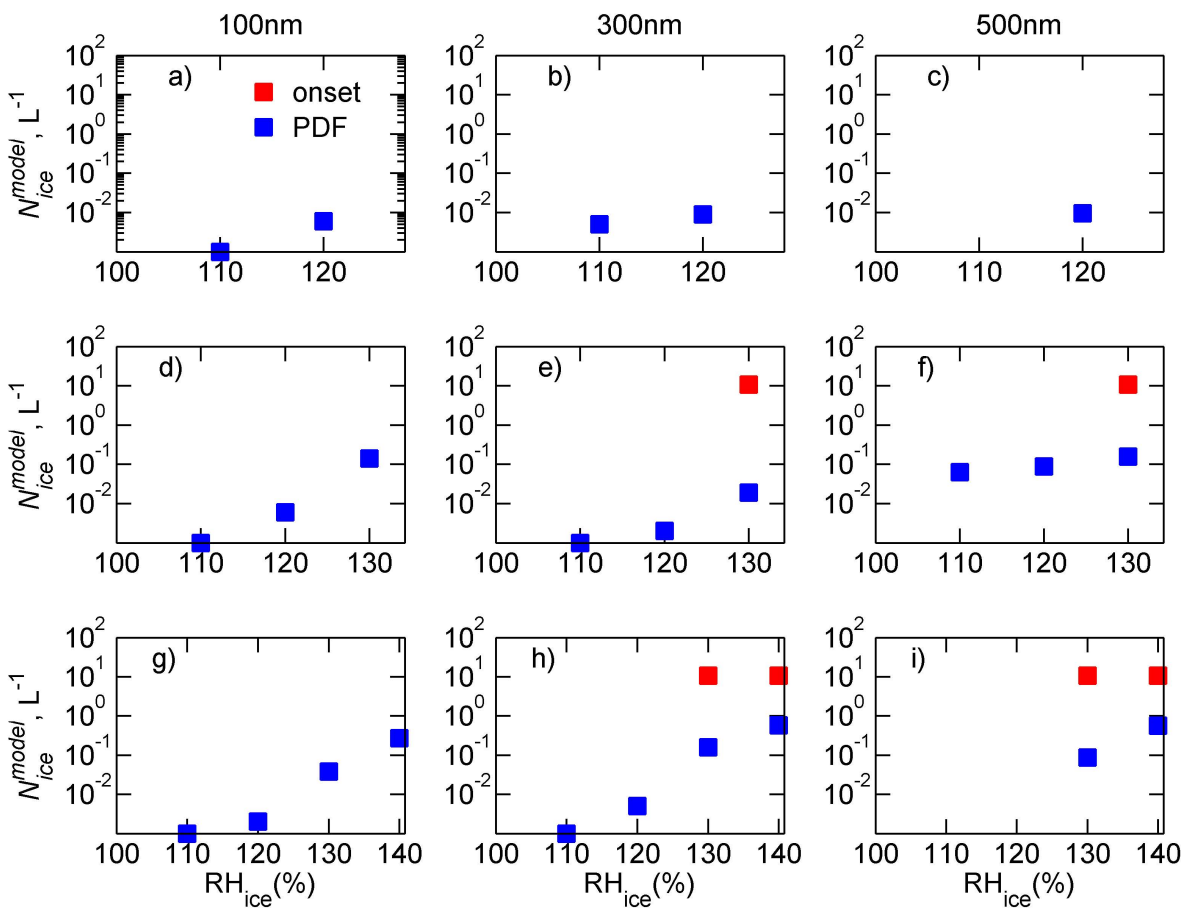

Fig. 6. Comparison of $N_{\text {ice }}^{\text {model }}$ calculated by the single onset contact angle and PDF-contact angle approaches under various IN measurement conditions (Table 1). (a) to (c), (d) to (f) and (g) to (i) correspond to $-25,-30$ and $-35^{\circ} \mathrm{C}$, respectively.

would be expected by CNT, and may be due to experimental $\mathrm{RH}_{\text {ice }}$ uncertainty. For example, larger size particles could nucleate at lower onset $\mathrm{RH}_{\text {ice }}$ than smaller size dust particles due to the differences in surface area. This premise was verified using CNT, where the sensitivity of onset $\mathrm{RH}_{\text {ice }}$ to the dust particle size was investigated keeping all other parameters in Eqs. (1) to (3) constant. We observed that for $500 \mathrm{~nm}$ particles, the onset $\mathrm{RH}_{\text {ice }}$ was decreased by $\sim 2 \%$ compared to $100 \mathrm{~nm}$ particles. The difference between these two onset $\mathrm{RH}_{\text {ice }}$ magnitudes is still less than the experimental $\mathrm{RH}_{\text {ice }}$ uncertainty ( $\sim 3 \%$ in this study), and therefore we would not be able to distinguish the size effect at onset conditions.

\subsection{Sensitivity to single onset contact angle and PDF-contact angle approaches}

Ice number concentration $\left(N_{\text {ice }}^{\text {model }}\right)$ were calculated using offline modules of CNT that consist of two approaches: single onset contact angle and PDF- $\theta$. The results from both these tests are shown in Fig. 6. The tests are run for dust sizes of 100,300 and $500 \mathrm{~nm}$ at temperatures of $-25,-30$ and $-35^{\circ} \mathrm{C}$, respectively, initialized with $N_{0}$ of $10.7 \mathrm{~L}^{-1}$ and at $\mathrm{RH}_{\text {ice }}$ values between $110 \%$ and $140 \%$ in $10 \%$ increments with an integration time step of $2 \mathrm{~s}$. For all the simulations, the onset approach predicted zero $N_{\text {ice }}^{\text {model }}$ at low humidity ranges and showed a step function (jump in the $N_{\text {ice }}^{\text {model }}$ from zero to maximum) with an increase in the $\mathrm{RH}_{\text {ice }}$, except that at panels a to $\mathrm{d}$ and $\mathrm{g}$ conditions there is no ice activation from the onset approach. Whereas the PDF approach predicted non-zero $N_{\text {ice }}^{\text {model }}$, and their magnitudes were lower than those from the onset approach; see panels e, f, h and i.

Different sensitivity of $N_{\text {ice }}^{\text {model }}$ as a function of $\mathrm{RH}_{\text {ice }}$ can be attributed to different representations (single contact angle verses PDF- $\theta$ ) of ice nucleating properties. Onset single contact angles are calculated at one $\mathrm{RH}_{\text {ice }}$ magnitude, whereas the PDF- $\theta$ approach uses many experimental data points to calculate the PDF parameters. In ice clouds, larger $N_{\text {ice }}^{\text {model }}$ would result in smaller ice particle effective radius and an increase in cloud albedo. Consequently, the large $N_{\text {ice }}^{\text {model }}$ simulated in models due to assumptions pertaining to IN parameterizations could have a significant impact on cloud microphysical and radiative properties. Here, it was shown that nearly all particles are activated at one particular $\mathrm{RH}_{\text {ice }}$ predicted by the single contact angle parameterization, while ice number predicted by the PDF- $\theta$ approach gradually increases with increasing $\mathrm{RH}_{\text {ice }}$. This difference will further influence cloud properties (Eidhammer et al., 2009) and climate (Liu et al., 2012).

\subsection{Cloud property sensitivity to the single contact angle and PDF parameters with CRM}

Figure 7 shows the horizontal domain- and time-averaged vertical profiles of $N_{i}$ and IWC from the CRM simulations for the single contact angle approach. Clouds generally form 

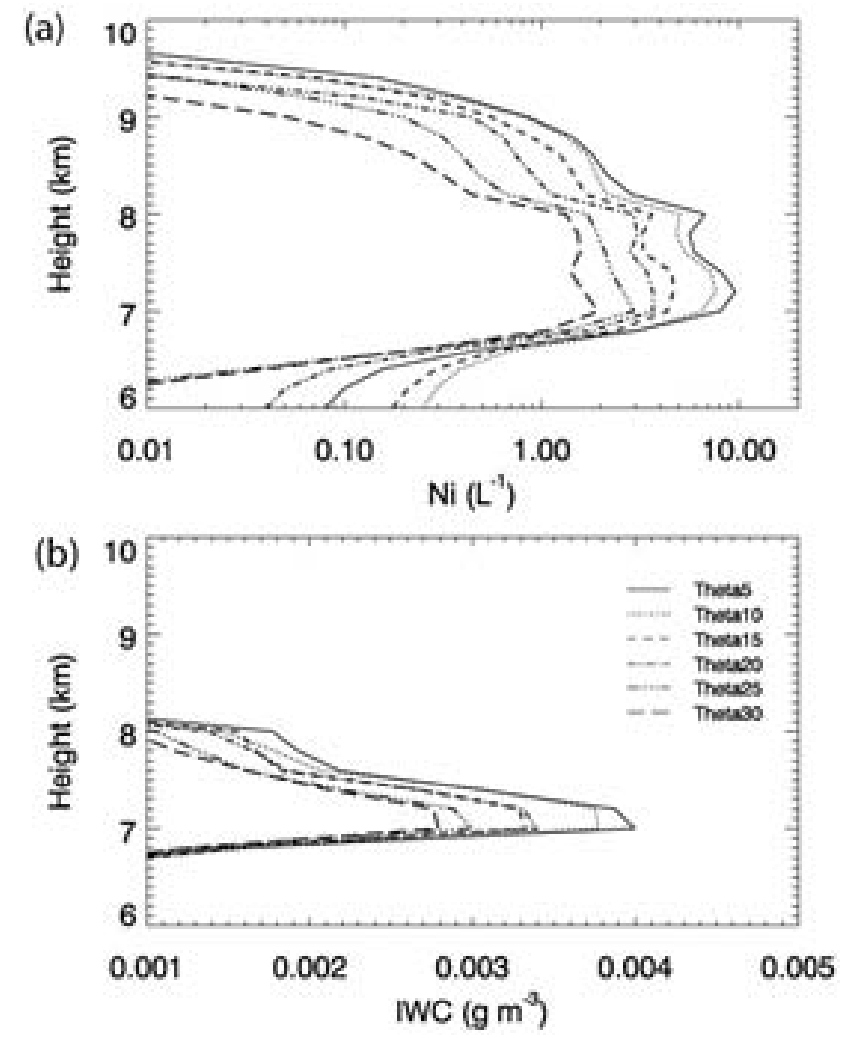

Fig. 7. Horizontal domain and time averaged (a) vertical profiles of $N_{i}$ and (b) IWC simulated in the CRM under different onset single contact angle. Increase in the contact angles (shown as ThetaX, where $\mathrm{X}$ is contact angle in degrees) results in the decrease of $N_{i}$ and IWC.

at the temperature range from -27 to $-14^{\circ} \mathrm{C}$ in our simulations. It is shown that cloud microphysical properties are sensitive to the change of contact angle; as the contact angle increases, $N_{i}$ and IWC decrease. The maximum $N_{i}$ and IWC occur at approximately $7.2 \mathrm{~km}$ altitude. At this height, when contact angle is increased from 5 to 30 degree, $N_{i}$ and IWC decrease by $80 \%$ and $30 \%$, respectively. The cloud depth decreases as the contact angle increases (Fig. 7b).

Cloud initiation time is also sensitive to the contact angle as shown from the time-series of $N_{i}$ (Fig. 8). The cloud structure (shape of the cloud and $N_{i}$ ) is similar over the entire simulation time as the contact angle is increased from 5 to 10 degrees. At some periods of evolution, the $N_{i}$ is equal to $N_{0}$, meaning ice nucleation is very efficient for dust with such low contact angles and all dust particles are activated. When the contact angle is increased to 15 degrees, the cloud initiation time is similar to the 5 and 10-degree simulations but the cloud structure is different. For clouds simulated at larger contact angles, i.e. at 20, 25 and 30 degrees, the cloud initiation time is delayed by approximately $0.5,3.8$ and $6.0 \mathrm{~h}$, respectively. In these three cases the predicted $N_{i}$ is smaller than the $N_{0}$, suggesting lower nucleation rates for dust par-
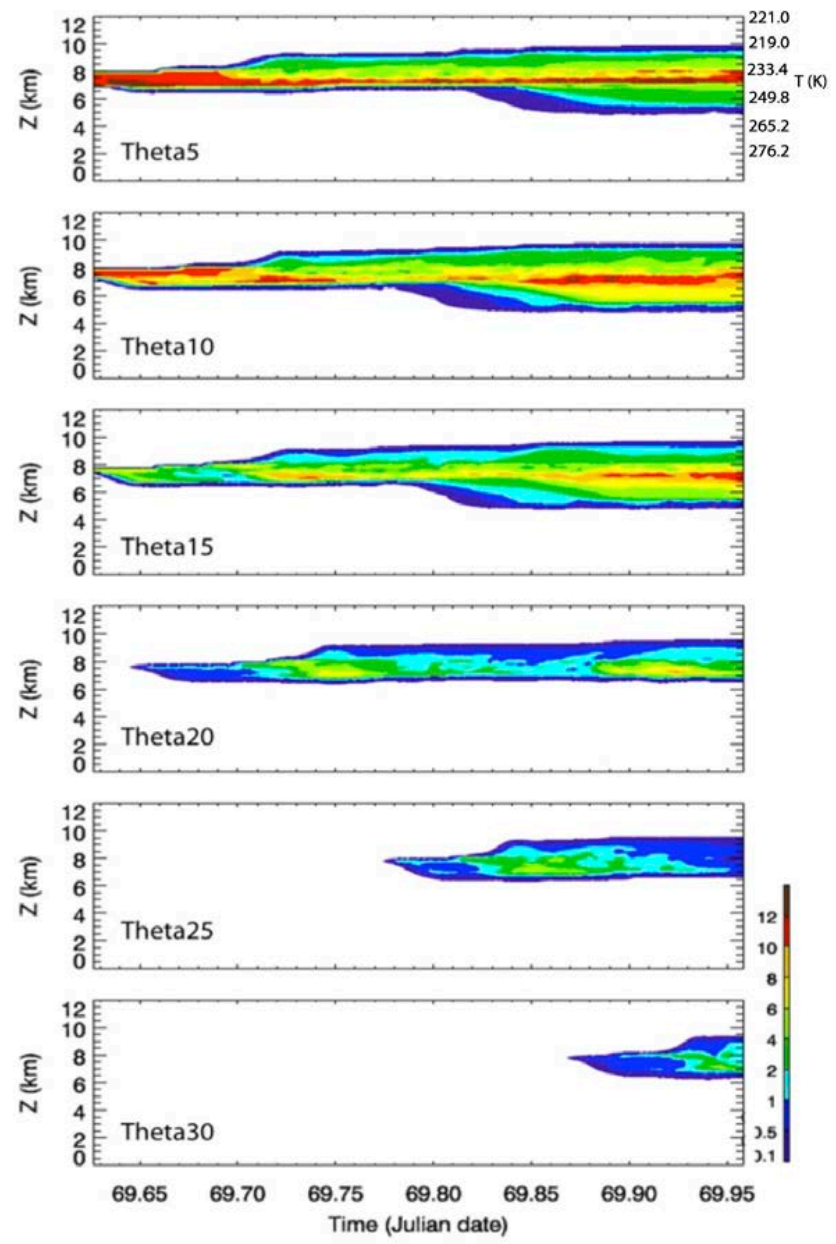

Fig. 8. Time series of vertical profile of cloud $N_{i}$ (horizontal domain-average) simulated using CRM. The total cloud evolution time simulated was $\sim 8 \mathrm{~h}$. Each panel shows the cloud structure under different onset single contact angle (shown as ThetaX, where $\mathrm{X}$ is contact angle in degrees). The $N_{0}$ was $10.7 \mathrm{~L}^{-1}$ in each case. The cloud structure and initiation time are sensitive to the contact angles. The color bar shows $N_{i}$.

ticles with larger contact angles. In general, cloud formation is delayed and cloud base height is higher with the increase of contact angle (Fig. 8). But it should be noted that higher cloud height does not necessarily mean higher $\mathrm{RH}_{\text {ice }}$.

Cloud sensitivity tests were also performed at various $\sigma$, $\mu$, and $N_{0}$ (Table 3 ) with the PDF- $\theta$ approach. Three sets of tests were simulated: first we varied $\mu$ by fixing $\sigma$, then we varied $\sigma$ by fixing $\mu$, and in the third case we varied the $N_{0}$ with fixed $\sigma$ and $\mu$. Results indicate that cloud thickness is sensitive to $\mu$ and $N_{0}$ but not to $\sigma$ (Fig. 9). The $N_{i}$ and IWC averaged over the cloudy points are also more sensitive to $\mu$ than $\sigma$. As $\mu$ is decreased from 38.0 to 23.0 degrees, $N_{i}$ increases by more than 2-3 times and IWC by about $25 \%$, comparable to the increases resulted from about 9 times increase in $N_{0}$. Note that the cloud properties are only sensitive to the change of $\mu$ at some certain range: dramatic increases 
(a)

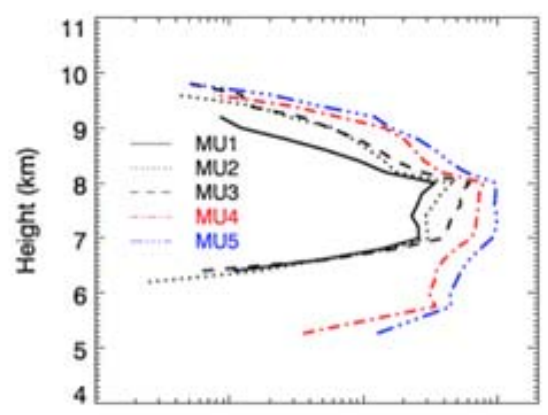

(b)

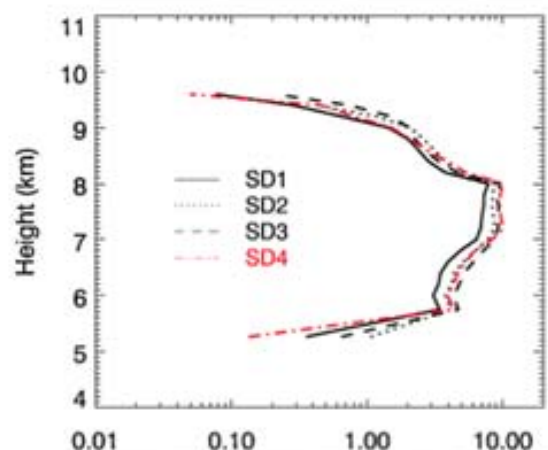

(c)

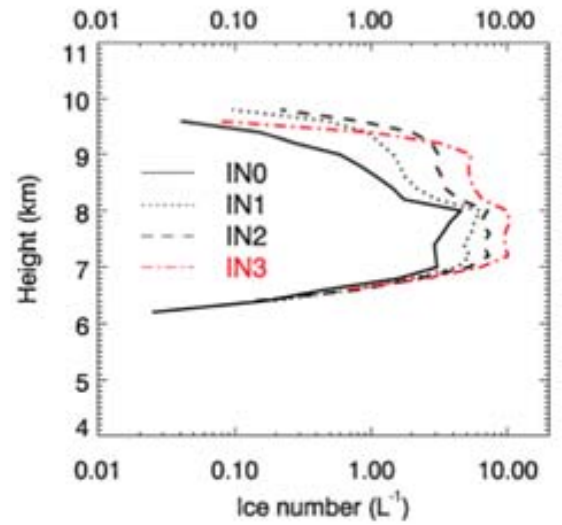

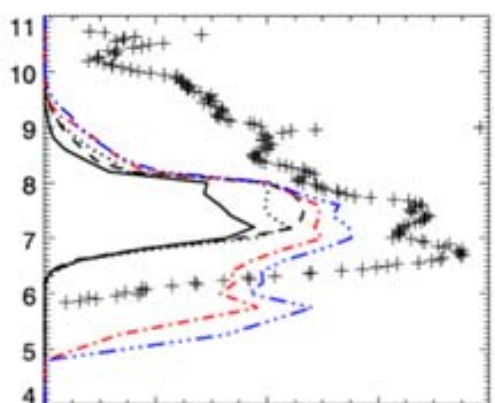
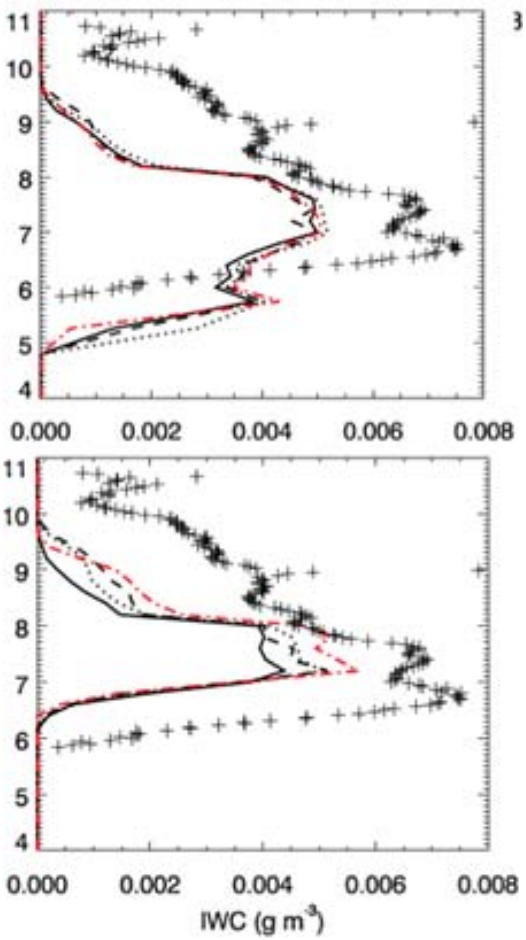

Fig. 9. $N_{i}$ and IWC averaged over the cloudy-points from the sensitivity tests of (a) $\mu$ (MU), (b) $\sigma$ (SD), and (c) $N_{0}$ simulated in the CRM. See Table 3 for details. The observed IWC (+) was retrieved from the ground-based lidar and radar observations (Comstock et al., 2007).

of cloud thickness, $N_{i}$ and IWC are seen when $\mu$ is decreased from 28 to 23 degrees. Both $N_{i}$ and IWC are sensitive to the $N_{0}$ (Fig. 9c) and, as expected, an increase in the $N_{0}$ results in an increase of both $N_{i}$ and IWC. Note that the simulated IWC (Fig. 9) is still much smaller than the retrieved values from the ground-based remote-sensing observations, especially above the height of $8.5 \mathrm{~km}$. At these altitudes the temperatures are colder than $-40^{\circ} \mathrm{C}$, and homogeneous freezing of aerosol could be the dominant mechanism as indicated by Sölch and Kärcher (2011). This ice formation mechanism is not considered in our tests. The main purpose here is to test the cloud sensitivity to different parameters for deposition nucleation only, instead of producing a good simulation to match the observations. Other three heterogeneous ice nucleation mechanisms (condensation, immersion, and contact) are also not included in our simulations.
Based on CNT, we know that the smaller contact angles correspond to the higher ice nucleation efficiency compared to the particles characterized by larger contact angles. For example, Chen et al. (2008) compared the contact angles for various particles and in general, mineral dust particles had smaller contact angles compared to uncoated soot particles. From the literature, we know that dust is a good IN (e.g. Möhler et al., 2006; Eastwood et al., 2008; Kanji and Abbatt, 2006; Welti et al., 2010) compared to uncoated soot (e.g. Dymarska et al., 2006; Koehler et al., 2009; Friedman et al., 2011) because it nucleates at relatively lower $\mathrm{RH}_{\text {ice }}$ at the same temperature. Cloud simulations show that it becomes more difficult to nucleate particles as the contact angle increases (Fig. 7a). Although our version of CNT does not directly include information of aerosol chemical composition and coating, the simulations with the larger contact angles can be associated with the particles that have poor ice 
nucleating properties. This leads to delay in cloud formation (Fig. 8) that might delay the onset of precipitation, and therefore could affect the weather and climate.

The decrease in $\mu$ results in a contact angle distribution that shifts towards smaller values, which leads to the larger $N_{i}$ and IWC (Fig. 9a). The cloud depth also varies in these cases (Fig. 9), which would affect cloud radiative forcing and cloud lifetime. Based on the simulations presented here, we find that $\sigma$ is not as important as $\mu$ in terms of the effects on cloud properties. However, other extreme values of $\sigma$ (e.g. $\sigma$ equal to tenth of a percent) need to be investigated in the future to confirm our understanding. This information may help to simplify the relationship between the PDF parameters if we only need to include the variability of the $\mu$ parameter. In the last case (Fig. 9c), it is evident that as more particles serve as an IN, under favorable ice nucleation conditions (low temperature and high $\mathrm{RH}_{\mathrm{ice}}$ ), it would lead to the larger $N_{i}$ and IWC. This simulation was carried out to understand the sensitivity of $N_{i}$ and IWC to $N_{0}$ using fixed $\sigma$ and $\mu$. Although the sensitivities to the PDF parameters are conducted under the relatively low $N_{0}\left(10.7 \mathrm{~L}^{-1}\right)$, the results on cloud sensitivity to contact angle and PDF parameters are not expected to change qualitatively at the higher $N_{0}$ since the fraction of activated IN is determined by the PDF parameters, not the $N_{0}$. Certainly, $N_{0}$ will change cloud properties of a single case. It is a necessary quantity to be known to examine aerosol effects on clouds. Also, changing the breadth of dust distribution will certainly affect ice formation. But the results of the sensitivity to the PDF parameters are not expected to change qualitatively at different dust size distributions for the same reason.

\subsection{PDF parameter comparison with the literature data}

The PDF parameters can be used as a proxy for comparing the IN measurements. To illustrate the idea, ice nucleation measurements were carried out using ATD and kaolinite dust particles at two different temperatures (Table 2) to compare the measurements with Welti et al. (2009). Keeping similar experimental conditions helped to compare the PDF parameters directly with each other. The comparison showed that there is a general agreement among the onset single contact angles, and these values are in agreement with the previous studies (Wang and Knopf, 2011 and references therein). But discrepancies exist within the PDF parameters, which could be attributed to the dust surface inhomogeneities, uncertainties within the measurements (e.g. $\mathrm{RH}_{\text {ice }}$ ) and the ice chamber operational conditions (e.g. ice crystal detection threshold; bath cooling rates; see Sect. 2.1).

Based on the onset $\mathrm{RH}_{\text {ice }}$ and dust surface area available for the deposition nucleation, Wheeler and Bertram (2012) calculated the PDF parameters for kaolinite and illite dust samples. Direct comparison with their PDF parameters for kaolinite at their $-34{ }^{\circ} \mathrm{C}$ with our results at $-35{ }^{\circ} \mathrm{C}$, assuming within temperature uncertainty limits, showed disagree- ments. They reported $\mu$ and $\sigma$ as 0.0 deg and $0.944 \mathrm{rad}$ while we calculated $56.0 \mathrm{deg}$ and $0.49 \mathrm{rad}$, respectively.

Recently, Kanji et al. (2011) reported the results from the Fourth International Ice Nucleation Workshop (DeMott et al., 2008). The results indicate good agreement between IN measurements carried out by three different ice chamber instruments (two of them are continuous flow diffusion chambers and the other is the expansion-type cloud chamber); however, absolute differences in calculated onset temperature and $\mathrm{RH}_{\text {ice }}$ were noted. The study highlighted the importance of ice crystal detection threshold, experimental technique and low temperature kinetic effects on IN measurements. Comparing our results with Wheeler and Bertram (2012), the factors such as ice crystal detection threshold and experimental technique could have contributed to observed disagreements. Other factors, such as dust surface area and particle residence time in the chamber, could also have played a role. We think minimizing the contribution from these factors would help to compare the IN measurements in future.

\section{Summary and future work}

Deposition ice nucleation experiments were carried out to investigate the ice nucleating properties of $100,300,400$ and $500 \mathrm{~nm}$ diameter dust particles at $-25,-30$ and $-35^{\circ} \mathrm{C}$ temperatures. These properties were parameterized using CNT based PDF- $\theta$ and onset single contact angle parameterizations, and the sensitivity of cloud properties $\left(N_{i}\right.$, IWC and cloud initiation time) to these parameterizations were investigated using offline module tests and CRM simulations.

The main conclusions from this study are as follows:

1. In the module tests of CNT, larger $N_{\text {ice }}^{\text {model }}$ are simulated with the onset single contact angle approach compared with the PDF representation, which could result in smaller ice crystal radii and might affect cloud microphysical and radiative properties.

2. As expected on the basis of CNT, cloud properties are sensitive to the contact angles. An increase in the contact angle results in a decrease in $N_{i}$ and IWC. Also the cloud initiation time is delayed by $\sim 6 \mathrm{~h}$ when the contact angles are increased from 5 to 30 degrees.

3. Both $N_{i}$ and IWC increase with a decrease in $\mu$, while they are not very sensitive to $\sigma \cdot N_{i}$ increases by more than 2-3 times and IWC increases by about $25 \%$, when $\mu$ decreases from 38 to 23 degrees. The modeled cloud properties are highly sensitive to a certain range of $\mu$. When $\mu$ is decreased from 28 to 23 degrees we observed increase in the cloud thickness, $N_{i}$ and IWC. Also as expected an increase of $N_{0}$ leads to an increase in $N_{i}$ and IWC. Overall, this implies that the cloud properties are sensitive to the PDF parameters. 
4. Calculated onset single contact angles are consistent with the literature data, but discrepancies within the PDF parameters exist. Definite reasons for the discrepancy cannot be understood at this time, but several factors like dust physiochemical properties and IN measurement procedure might be responsible.

Cloud properties are sensitive to the magnitude and representation method of contact angles, implying that accurate representation of contact angle is crucial to simulate icecontaining clouds in models. Therefore, for the purpose of applying CNT to represent atmospheric ice nucleation, experimental methods applied to obtain the contact angles need to be standardized in the future (Cantrell and Heymsfield 2005). Also it should be noted that a recent study (Wheeler and Bertram, 2012) showed that single contact angle approach is not suitable to parameterize heterogeneous ice nucleation. However, further studies are required to validate this finding outside the temperature range they studied.

There are a number of previous studies (e.g. Möhler et al., 2006; Welti et al., 2009; Kulkarni and Dobbie, 2010; Jones et al., 2011) that have investigated the ice nucleating properties of various dust types. These available measurements can be used to calculate the PDF parameters and a matrix of such PDF parameters then can be examined for a relationship to simplify the parameterization task. The task can be further improved by employing quality controlled data sets, e.g. incorporating experimental measurement errors and obtaining data of larger particle sizes that have limited multiple charge particle influence, for different ice nucleation research groups to calculate the PDF parameters that can be compared with one another to understand the ice nucleating properties of aerosol particles. More cloud sensitivity studies (e.g. Niemand et al., 2012; Ervens and Feingold, 2012) that includes comparison of various parameterizations to the measurements are needed in order to identify the parameterizations that sufficiently describe the ice formation.

\section{Supplementary material related to this article is available online at: http://www.atmos-chem-phys.net/12/ 7295/2012/acp-12-7295-2012-supplement.pdf.}

Acknowledgements. We acknowledge the support from PNNL Aerosol-Climate Initiative (ACI). We thank Steven Ghan and Andrew Welti for the project support and providing laboratory data, respectively. The Pacific Northwest National Laboratory is operated for DOE by Battelle Memorial Institute under contract DE-AC06-76RLO 1830. We thank three anonymous reviewers and Editor Ottmar Möhler for providing the important comments, which have helped to improve the quality of the manuscript. We also thank Nitin Bharadwaj for Matlab programming support.

Edited by: O. Möhler

\section{References}

Baron, P. A. and Willeke, K.: Aerosol Measurement: Principles, Techniques, and Applications, 2nd Ed., Wiley-Interscience Publications, 2001.

Cantrell, W. and Heymsfield, A. J.: Production of ice in tropospheric clouds - A review, B. Am. Meteorol. Soc., 86, 795-807, 2005.

Chen, J.-P., Hazra, A., and Levin, Z.: Parameterizing ice nucleation rates using contact angle and activation energy derived from laboratory data, Atmos. Chem. Phys., 8, 7431-7449, doi:10.5194/acp-8-7431-2008, 2008.

Chernoff, D. I. and Bertram, A. K.: Effects of sulfate coatings on the ice nucleation properties of a biological ice nucleus and several types of minerals, J. Geophys. Res., 115, D20205, doi:10.1029/2010JD014254, 2010.

Comstock, J. M., D’Entremont, R., De Slover, D., Mace, G. G., Matrosov, S. Y., McFarlane, S. A., Minnis, P., Mitchell, D., Sassen, K., Shupe, M. D., Turner, D. D., and Wang, Z.: An intercomparison of microphysical retrieval algorithms for upper-tropospheric ice clouds, B. Am. Meteorol. Soc., 88, 191-204, 2007.

Connolly, P. J., Möhler, O., Field, P. R., Saathoff, H., Burgess, R., Choularton, T., and Gallagher, M.: Studies of heterogeneous freezing by three different desert dust samples, Atmos. Chem. Phys., 9, 2805-2824, doi:10.5194/acp-9-2805-2009, 2009.

Crowe, C. T.: Multiphase flow handbook, CRC Press, Taylor and Francis Group, LLC, FL, USA, 1-15-1-17, 2006.

Cziczo D. J., Thomson, D. S., Thompson, T. L., DeMott, P. J., and Murphy, D. J. M.: Particle analysis by laser mass spectrometry (PALMS) studies of ice nuclei and other low number density particles, Int. J. Mass Spectrom., 258, 21-29, 2006.

Cziczo D. J., Froyd, K. D., Gallavardin, S. J., Moehler, O., Benz, S., Saathoff, H., and Murphy, D. M.: Deactivation of ice nuclei due to atmospherically relevant surface coatings, Environ. Res. Lett. 4, 044013, doi:10.1088/1748-9326/4/4/044013, 2009.

DeMott, P. J., Möhler, O., Stetzer, O., Murakami, M., Bundke, U., Kanji, Z., Cotton, R., Jones, H., Leisner, T., Klein, H., Cziczo, D., Petters, M., Prenni, A., Abbatt, J., Saito, A., Ardon, K., Levin, Z., Bingemer, H., Sierau, B., Nicolet, M., Bowels, J., Gallavardin, S., Targino, A., Dorsey, J., Georgakopolous, D., Rzesanke, D., Brinkmann, M., Schwartz, T., Benz, S., Wagner, R., Saathoff, H., Ebert, V., Team, O. A., and Vali, G.: The Fourth International Ice Nucleation Workshop (ICIS-2007): Objectives and Preliminary Results Proceedings of 15th ICCP, Cancun, Mexico, 7-11 July 2008.

DeMott, P. J., Prenni, A. J., Liu, X., Kreidenweis, S. M., Petters, M. D., Twohy, C. H., Richardson, M. S., Eidhammer, T., and Rogers, D. C.: Predicting global atmospheric ice nuclei distributions and their impacts on climate, Proc. Natl. Acad. Sci., USA, 107, 11217-11222, 2010.

Dymarska, M., Murray, B. J., Sun, L. M., Eastwood, M. L., Knopf, D. A., and Bertram, A. K.: Deposition ice nucleation on soot at temperatures relevant for the lower troposphere, J. Geophys. Res., 111, D04204, doi:10.1029/2005JD006627, 2006.

Eastwood, M. L., Cremel, S., Gehrke, C., Girard, E., and Bertram, A. K.: Ice nucleation on mineral dust particles: Onset conditions, nucleation rates and contact angles, J. Geophys. Res., 113, D22203, doi:10.1029/2008JD010639, 2008.

Eidhammer, T., DeMott, P. J., and Kreidenweis, S. M.: A comparison of heterogeneous ice nucleation parameterizations using a parcel model framework, J. Geophys. Res., 114, D06202, 
doi:10.1029/2008JD011095, 2009.

Ervens, B. and Feingold, G.: On the representation of immersion and condensation freezing in cloud models using different nucleation schemes, Atmos. Chem. Phys., 12, 5807-5826, doi:10.5194/acp-12-5807-2012, 2012.

Fan, J., Ovtchinnikov, M., Comstock, J., McFarlane, S. A., and Khain, A.: Ice formation in Arctic mixed-phase clouds: Insights from a 3-D cloud-resolving model with size-resolved aerosol and cloud microphysics, J. Geophys. Res., 114, D04205, doi:10.1029/2008JD010782, 2009.

Fletcher, N. H.: Physics of Rainclouds, Cambridge University Press, Cambridge, 52-53, 1962.

Forster, P. M., Ramaswamy, V., Artaxo, P., Berntsen, T., Betts, R., Fahey, D. W., Haywood, J., Lean, J., Lowe, D. C., Myhre, G., Nganga, J., Prinn, R., Raga, G., Schultz, M., and Van Dorland, R.: Changes in Atmospheric Constituents and in Radiative Forcing, edited by: Solomon, S., Qin, D., Manning, M., Chen, Z., Marquis, M., Averyt, K., Tignor, M., Miller, H. L., Climate Change 2007: The Physical Science Basis. Contribution of Working Group I to the Fourth Assessment Report of the Intergovernmental Panel on Climate Change, Cambridge University Press, 2007.

Friedman, B., Kulkarni, G., Beránek, J., Zelenyuk, A., Thornton, J., and Cziczo, D.: Ice Nucleation and Droplet Formation by Bare and Coated Soot Particles, J. Geophys. Res., 116, D17203, doi:10.1029/2011JD015999, 2011.

Ervens, B. and Feingold, G.: On the representation of immersion and condensation freezing in cloud models using different nucleation schemes, Atmos. Chem. Phys., 12, 5807-5826, doi:10.5194/acp-12-5807-2012, 2012.

Heymsfield, A. J. and Miloshevich, L. M.: Relative Humidity and Temperature Influences on Cirrus Formation and Evolution: Observations from Wave Clouds and FIRE II, J. Atmos. Sci., 52, 4302-4326, 1995.

Hoose, C., Kristjánsson, J. E., Chen, J. P., and Hazra, A.: A classical-theory-based parameterization of heterogeneous ice nucleation by mineral dust, soot and biological particles in a global climate model, J. Atmos. Sci., 67, 2483-2503, 2010.

Kanji, Z. A. and Abbatt, J. P. D.: Laboratory studies of ice formation via deposition mode nucleation onto mineral dust and n-hexane soot samples, J. Geophys. Res., 111, D16204, doi:10.1029/2005JD006766, 2006.

Kanji, Z. A. and Abbatt, J. P. D.: Ice Nucleation onto Arizona Test Dust at Cirrus Temperatures: Effect of Temperature and Aerosol Size on Onset Relative Humidity, J. Phys. Chem. A, 114, 935941, 2010

Kanji, Z. A., DeMott, P. J., Möhler, O., and Abbatt, J. P. D.: Results from the University of Toronto continuous flow diffusion chamber at ICIS 2007: instrument intercomparison and ice onsets for different aerosol types, Atmos. Chem. Phys., 11, 31-41, doi:10.5194/acp-11-31-2011, 2011.

Khain, A., Pokrovsky, P. A., Pinsky, M., Seifert, A., and Phillips, V.: Simulation of effects of atmospheric aerosols on deep turbulent convective clouds using a spectral microphysics mixedphase cumulus cloud model: I. Model description and possible applications, J. Atmos. Sci., 61, 2963-2982, 2004.

Khain, A., BenMoshe, N. and Pokrovsky, A.: Factors determining the impact of aerosols on surface precipitation from clouds: An attempt at classification, J. Atmos. Sci., 65, 1721-1748, 2008.
Khairoutdinov, M. F. and Randall, D. A.: Cloud resolving modeling of the ARM summer 1997 IOP: Model formulation, results, uncertainties, and sensitivities, J. Atmos. Sci., 60, 607-625, doi:10.1175/1520-0469, 2003.

Khvorostyanov, V. I. and Curry, J. A.: A new theory of heterogeneous ice nucleation for application in cloud and climate models, Geophys. Res. Lett., 27, 4081-4084, 2000.

Khvorostyanov, V. I. and Curry, J. A.: The theory of ice nucleation by heterogeneous freezing of deliquescent mixed CCN. Part 1: Critical radius, energy and nucleation rate, J. Atmos. Sci., 61, 2676-2691, 2004.

Koehler, K. A., DeMott, P. J., Kreidenweis, S. M., Popovicheva, O. B., Petters, M. D., Carrico, C. M., Kireeva, E. D., Khokhlova, T. D., and Shonija, N. K.: Cloud condensation nuclei and ice nucleation activity of hydrophobic and hydrophilic soot particles, Phys. Chem. Chem. Phys., 11, 7906-7920, 2009.

Koop, T., Luo, B., Tsias, A. and Peter, T.: Water Activity as the Determinant for Homogeneous Ice Nucleation in Aqueous Solutions, Nature, 406, 611-614, 2000

Kulkarni, G. and Dobbie, S.: Ice nucleation properties of mineral dust particles: determination of onset RHi, IN active fraction, nucleation time-lag, and the effect of active sites on contact angles, Atmos. Chem. Phys., 10, 95-105, doi:10.5194/acp-10-95-2010, 2010.

Liu, X. and Penner, J.: Ice nucleation parameterization for global models, Meteorol. Z., 14, 499-514, 2005.

Liu, X., Shi, X., Zhang, K., Jensen, E. J., Gettelman, A., Barahona, D., Nenes, A., and Lawson, P.: Sensitivity studies of dust ice nuclei effect on cirrus clouds with the Community Atmosphere Model CAM5, Atmos. Chem. Phys. Discuss., 12, 13119-13160, doi:10.5194/acpd-12-13119-2012, 2012.

Lüönd, F., Stetzer, O., Welti, A., and Lohmann, U.: Experimental study on the ice nucleation ability of size-selected kaolinite particles in the immersion mode, J. Geophys. Res., 115, D14201, doi:10.1029/2009JD012959, 2010.

Marcolli, C., Gedamke, S., Peter, T., and Zobrist, B.: Efficiency of immersion mode ice nucleation on surrogates of mineral dust, Atmos. Chem. Phys., 7, 5081-5091, doi:10.5194/acp-7-50812007, 2007.

Meyers M. P., DeMott P. J., and Cotton W. R.: New primary icenucleation parameterizations in an explicit cloud model, J. Appl. Meteorol., 31, 708-721, 1992.

Möhler, O., Field, P. R., Connolly, P., Benz, S., Saathoff, H., Schnaiter, M., Wagner, R., Cotton, R., Krämer, M., Mangold, A., and Heymsfield, A. J.: Efficiency of the deposition mode ice nucleation on mineral dust particles, Atmos. Chem. Phys., 6, 30073021, doi:10.5194/acp-6-3007-2006, 2006.

Niedermeier. D., Shaw, R. A., Hartmann, S., Wex, H., Clauss, T., Voigt, J., and Stratmann, F.: Heterogeneous ice nucleation: exploring the transition from stochastic to singular freezing behavior, Atmos. Chem. Phys., 11, 8767-8775, doi:10.5194/acp-118767-2011, 2011.

Niemand, M., Möhler, O., Vogel, B., Vogel, H., Hoose, C., Connolly, P., Klein, H., Bingemer, H., DeMott, P., Skrotzki, J., and Leisner, T.: A particle-surface-area based parameterization of immersion freezing on desert dust particles. J. Atmos. Sci., doi:10.1175/JAS-D-11-0249.1, in press, 2012.

Phillips V. T. J., DeMott P. J. and Andronache, C.: An empirical parameterization of heterogeneous ice nucleation for multi- 
ple chemical species of aerosol, J. Atmos. Sci., 65, 2757-2783, 2008.

Pruppacher, H. R. and Klett, J. D.: Microphysics of Clouds and Precipitation, Springer Publications, New York, USA, 287-361, 1997.

Sölch I. and Kärcher, B.: Process-oriented large-eddy simulations of a midlatitude cirrus cloud system based on observations. Q. J. Roy. Meteorol. Soc., 137, 374-393, 2011.

Stetzer, O., Baschek, B., Luond, F., and Lohmann, U.: The Zurich Ice Nucleation Chamber (ZINC)-A new Instrument to Investigate Atmospheric Ice Formation, Aerosol Sci. Technol., 42, 64-74, 2008.

Sullivan, R. C., Petters, M. D., DeMott, P. J., Kreidenweis, S. M., Wex, H., Niedermeier, D., Hartmann, S., Clauss, T., Stratmann, F., Reitz, P., Schneider, J., and Sierau, B.: Irreversible loss of ice nucleation active sites in mineral dust particles caused by sulphuric acid condensation, Atmos. Chem. Phys., 10, 1147111487, doi:10.5194/acp-10-11471-2010, 2010.
Tabazadeh, A., Jensen, E. J., and Toon, O. B.: A model description for cirrus cloud nucleation from homogeneous freezing of sulfuric acid aerosols, J. Geophys. Res., 102, 23845-23850, 1997.

Vali, G.: Nucleation Terminology, B. Am. Meteor. Soc., 66, 14261427, 1985.

Wang, B. and Knopf, D. A.: Heterogeneous ice nucleation on particles composed of humic-like substances impacted by O3, J. Geophys. Res., 116, D03205, doi:10.1029/2010JD014964, 2011.

Welti, A., Lüönd, F., Stetzer, O., and Lohmann, U.: Influence of particle size on the ice nucleating ability of mineral dusts, Atmos. Chem. Phys., 9, 6705-6715, doi:10.5194/acp-9-6705-2009, 2009.

Wheeler, M. J. and Bertram, A. K.: Deposition nucleation on mineral dust particles: a case against classical nucleation theory with the assumption of a single contact angle, Atmos. Chem. Phys., 12, 1189-1201, doi:10.5194/acp-12-1189-2012, 2012. 